\title{
A Comparative Study to Assess the Knowledge Regarding Food Adulteration and its Detection and to Create Awareness among Homemakers in Selected Rural and Urban Community of Durg District, Chhattisgarh
}

\author{
Susheela Indu
}

\begin{abstract}
Aims: The objectives of the study were (1) to identify the sociodemographic variables of rural and urban groups of homemakers, (2) to assess the knowledge of rural and urban homemakers regarding food adulteration and its detection, (3) to compare the knowledge of rural and urban homemakers regarding food adulteration and its detection, (4) to associate knowledge of the rural and urban homemakers regarding food adulteration and its detection with the selected sociodemographic variables, (5) to assess the buying practices and awareness regarding food safety standard symbols among rural and urban homemakers, and (6) to create awareness regarding food adulterants through group demonstration by detecting food adulterants in the selected food items.

Methods: A quantitative research approach and a non-experimental descriptive comparative survey design were used.

Results: The findings of the study revealed that among rural homemakers 15 (50\%) had poor knowledge; 8 (26.66\%) had average knowledge; $6(20 \%)$ had good knowledge; and 1 (3.33\%) had excellent knowledge, whereas among urban homemakers 14 (46.66\%) had poor knowledge; $7(23.33 \%)$ had average knowledge; 7 (23.33\%) had good knowledge; and 2 (6.66\%) had excellent knowledge. " $t$ " test revealed that there was no significant difference in mean scores of knowledge of rural and urban homemakers regarding food adulteration and its detection.

Conclusion: Appropriate knowledge regarding food adulteration, its detection, and consumer protection is an important component of public health because good nutrition benefits to everyone. A better informed public, supported by effective health information, would help people to make better food choices and prevent food-borne illnesses. Food safety and development of quality are joint responsibility of health professionals and consumers, and hence community health nurses play a crucial role in creating awareness among general public.

Keywords: Food adulteration, Homemakers.

Pondicherry Journal of Nursing (2019): 10.5005/jp-journals-10084-12112
\end{abstract}

\section{INTRODUCTION}

Health is wealth; happiness lies in the health of man. Good health helps to develop charm, grace, and happy mind. Florence Nightingale recognizes the radically changed outcomes by addressing clean water and providing nourishing food, light, and fresh air. ${ }^{1}$ Healthy individual realizes abilities, can cope with normal stresses of life, can work productively, and is able to make contribution to the community. ${ }^{2}$ Good nutritive food plays a very vital role in maintaining proper health and also helps in prevention and cure of diseases. All body functions such as metabolic, hormonal, mental, physical, or chemical cannot be performed by the body without nutritive food. ${ }^{3}$ For healthy mind, soul, or psyche, food itself needs to be healthy. Access to good quality food has been man's main endeavor from the earliest days of human existence. ${ }^{4}$

Safety of food is a basic requirement of food quality. "Food safety" implies absence of contaminants, adulterants, or any other substance that may make food injurious to health on an acute or chronic basis. $^{5}$

Food adulteration is the most dangerous problem related to nutrition. Adulteration can be defined as the inclusion of constituents whose presence is prohibited by regulation, custom, and practice or making impure by adding inferior or less desirable materials or elements in the food. Adulteration of foods can be intentional, unintentional, or natural. ${ }^{6}$ The Indian Council of Medical Research has stated that adulterants are hazardous and cause irreversible damage to the organs. The other synthetic compounds
Department of Nursing, Government College of Nursing, Ambikapur, Chhattisgarh, India

Corresponding Author: Susheela Indu, Department of Nursing, Government College of Nursing, Ambikapur, Chhattisgarh, India, Phone: +919584302766, e-mail: induindu435@gmail.com

How to cite this article: Indu S. A Comparative Study to Assess the Knowledge Regarding Food Adulteration and Its Detection and to Create Awareness among Homemakers in Selected Rural and Urban Community of Durg District, Chhattisgarh. Pon J Nurs 2019;12(2):31-37. Source of support: Nil

Conflict of interest: None

cause impairments, heart problems, cancer, and even death. The immediate effect of drinking adulterated milk with urea, caustic soda, and formalin is gastroenteritis, but the long-term effects are known to be far more serious. ${ }^{7}$ The Government of India records indicate that on an average $25-30 \%$ of edibles sold in the market is adulterated. Some examples of intentional adulteration are addition of water to milk, extraneous matter to spices, or the removal or substitution of milk solids from the natural product. ${ }^{8}$ The World Health Organization declared that exposure to chemicals in food can result in $3 \%$ of all developmental defects, such as neural tube and heart deformities, $25 \%$ genetic deformities, male sterility, neurobehavioral disorders, proliferative lung disease, and allergic sensitization. ${ }^{9}$ 
The objectives of the study:

- To identify the sociodemographic variables among rural and urban group of homemakers.

- To assess the knowledge among rural and urban homemakers related to food adulteration and its detection.

- To compare the knowledge of rural and urban homemakers regarding food adulteration and its detection.

- To associate the knowledge of the rural and urban homemakers related to food adulteration and its detection with selected sociodemographic variables.

- To assess buying practices and awareness regarding food safety standard symbols among rural and urban homemakers.

- To create awareness about food adulterants through group demonstration by detecting food adulterants in selected food items.

\section{Conceptual Framework}

The conceptual framework used in this study is Imogene King's Theory of Goal Attainment. ${ }^{10,11}$

\section{Self}

- Self is the individual whose perception and role influence that person's communication, interaction, and decision-making in groups. This focuses the process whereby individuals interact mutually to set goals that result in goal attainment.

\section{Perception}

- Each person's representation of reality.

In the present study, the investigator perceived lack of knowledge among homemakers of rural and urban community regarding food adulteration and its detection.

\section{Goal Setting}

- A process to achieve goals that are valued.

In the present study, goal setting is to increase knowledge of homemakers of rural and urban community regarding food adulteration and its detection.

\section{Transaction}

- Purposeful interaction leading to goal attainment. The essential components of transaction process include action and interaction.

During action phase, the investigator prepared self-structured interview schedule to assess the knowledge of homemakers of rural and urban community regarding food adulteration and demonstration to identify food adulterants and its detection using simple rapid test.

\section{Interaction}

- A process of perception and communication.

- Between person and environment.

- Between person and person.

- Represented by verbal behavior.

- Goal directed.

In the present study, interaction is done between researcher and homemakers of rural and urban community by administration of self-structured interview.

\section{Communication}

- Information from person to person.

- Information components of interaction.
- In the present study, communication is the different techniques presented by demonstration of food adulterant detection.

\section{Growth and Development}

- Continuous changes in individual.

In present study, growth and development refer to knowledge gain among homemakers of rural and urban community, thereby moving toward maturity and continuous change in their behavior in terms of selection of good food items and detection of food adulterant.

\section{Feedback}

It is the process that enables a system to regulate and save and provides information about transaction and interaction.

Feedback is not included in the present study (Flowchart 1).

The following literatures were reviewed to highlight the important concept of food adulteration and its detection which are organized under the following sections.

Section I-literature related to knowledge regarding food adulteration.

Section II-literature related to knowledge regarding consumer protection.

Section III-literature related to food adulterant detection.

\section{Research Design}

Nonexperimental descriptive comparative survey.

\section{Sample and Setting}

Thirty homemakers from rural community (Uttai, Durg, C.G.) and 30 homemakers from urban slum (Ruabandha Durg, C.G).

\section{Sampling Technique}

Nonprobability convenience sampling.

\section{Variables}

\section{Dependent Variable}

It is the condition or characteristics that appear/disappear or change as researcher introduces, removes, or changes independent variable. In the present study, knowledge of rural and urban homemakers regarding food adulteration and its detection is the dependent variable.

\section{Functional Variable}

The functional variables in the present study are age, religion, caste, educational status, occupation, income, type of family, food habits, shops used, purchase frequency, type of food purchased, major decision for purchasing food for the family, and mass media exposure (Flowchart 2).

\section{Description of Tool}

The tool consists of four sections, namely:

Section-A: sociodemographic data. This section consists of questions that deal with sociodemographic variables age, religion, caste, educational status, occupation, income, type of family, food habits, shops used, purchase frequency, type of food purchased, major decision for purchasing food for the family, and mass media exposure.

Section-B: self-structured interview schedule.

This part consists of 25 items to assess the knowledge regarding food adulteration and its detection. The three areas are, namely: 
Flowchart 1: Conceptual framework based on Imogene King's Theory of Goal Attainment

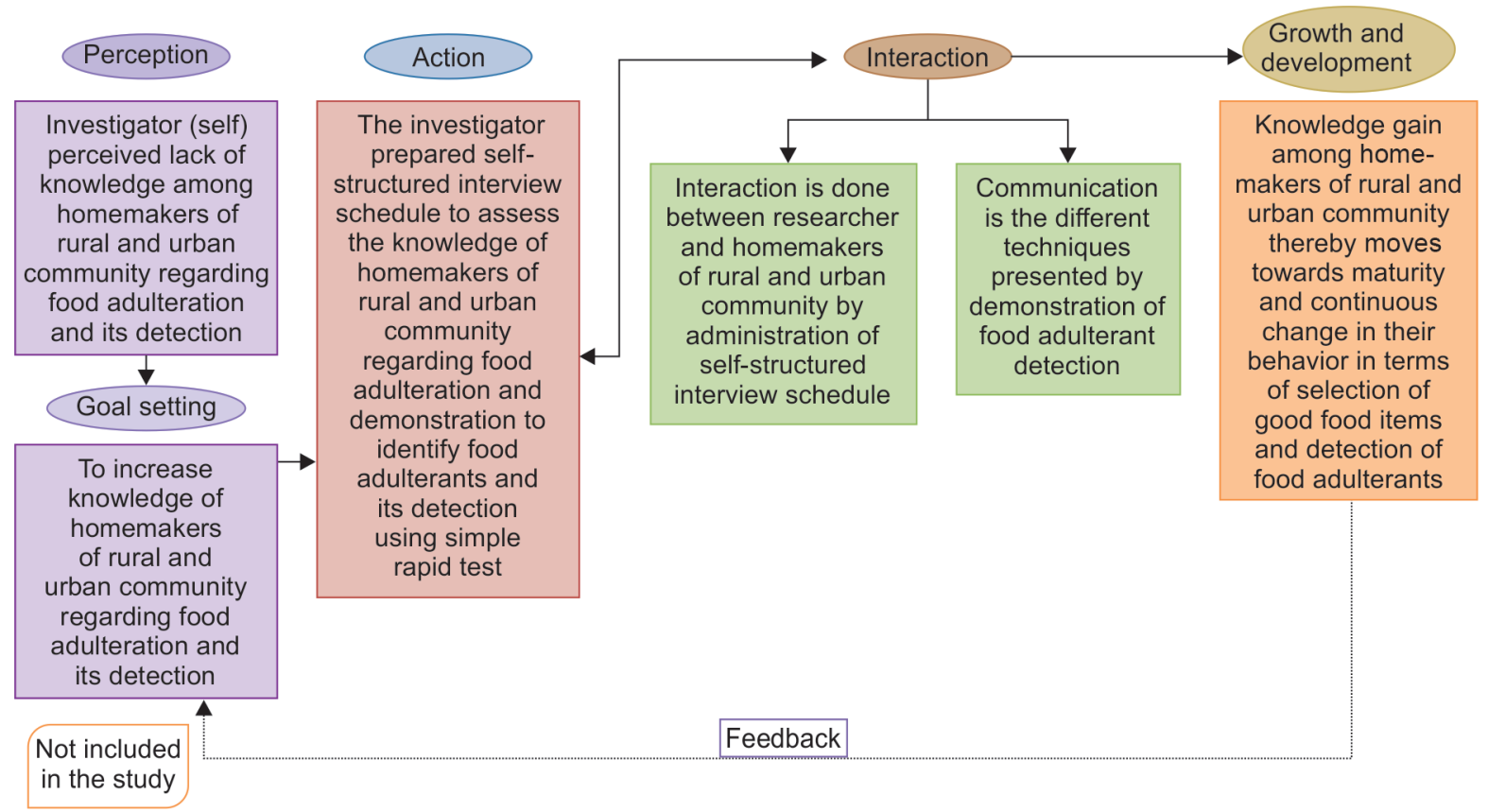

Food adulteration-10 items

Detection of food adulterant- 05 items

Consumer protection-10 items.

Each question carries 1 mark. Scoring was done as "1 mark" for each correct response and " 0 " for wrong answer or no response.

\section{Criterion Measure}

The criterion of the overall score of the knowledge is:

Poor-( $<13$ marks)

Average-(13-15 marks)

Good-(16-20 marks)

Excellent-(21-25 marks)

Section-C: this section consists of checklist regarding buying practices of respondents and awareness regarding food safety standard symbols. Buying practices such as packed sealed edible, check maximum retail price (MRP), check weight, check manufacture and expiry date, nutritional label were included, and rated as always, occasional, and never. Food safety standard symbols were asked to assess awareness and rated as aware and unaware.

Section-D: this section deals with simple rapid test for detection of adulterants in selected food items, namely, pulses (arhar daal, chana daal), red chili powder, turmeric powder, coriander powder, salt, milk, honey, asafetida, oil, ghee, black pepper, ice cream, tea, coffee, and sugar.

\section{Reliability}

The split half method was used to test the reliability of the tool, the test was first divided into two equivalent halves and correlation for the half test was found by using Karl Pearson's correlation coefficient formula. Since computed coefficient value was $r=0.7$, the reliability of the tool was established.

\section{Ethical Consideration}

For the present study, the investigator took into consideration the following ethical aspects:
- The research problem and objectives were approved by the research committee.

- Due permission from the authorities was obtained.

- Informed consent from participants was taken.

- Anonymity of the participants was ensured.

- Freedom to withdraw from the study any time.

\section{Results and Discussion}

\section{Part I-Description of Sociodemographic Variables}

Among rural and urban homemakers, majority of them, i.e., 14 (46.66\%) and 22 (73.33\%), respectively, belonged to age-group 21-30 years (Fig. 1). Among rural homemakers, the majority of them, i.e., 10 (33.33\%) had primary education; among urban homemakers, majority of them, i.e., 11 (36.66\%) had secondary education (Fig. 2); among rural and urban homemakers, majority of them, i.e., 16 (53.33\%) and 17 (56.66\%), respectively, were housewives (Fig. 3). Among both rural and urban homemakers, majority of them, i.e., 15 (50\%) and 13 (43.33\%), respectively, purchased food from general kirana (Fig. 4); for both rural and urban homemakers, majority of them, i.e., 20 (66.66\%) and 15 (50\%) were exposed to television (Fig. 5); among both rural homemakers 13 (43.33\%) and urban homemakers 11 (36.66\%) purchased food in loose form (Fig. 6).

\section{Part II-Assessment of the Knowledge of Rural and Urban Homemakers Regarding Food Adulteration and Its Detection}

Majority of both rural and urban homemakers (50\%) had poor knowledge (Fig. 7).

\section{Part III-Comparison of the Knowledge of Rural and Urban Homemakers}

"The computed value of " $t$ " was 0.473 which is less than the table value (2.00) at $p<0.05$; therefore, there is no significant difference in mean knowledge scores of rural and urban homemakers. 
Flowchart 2: Schematic representation of research design for the present study

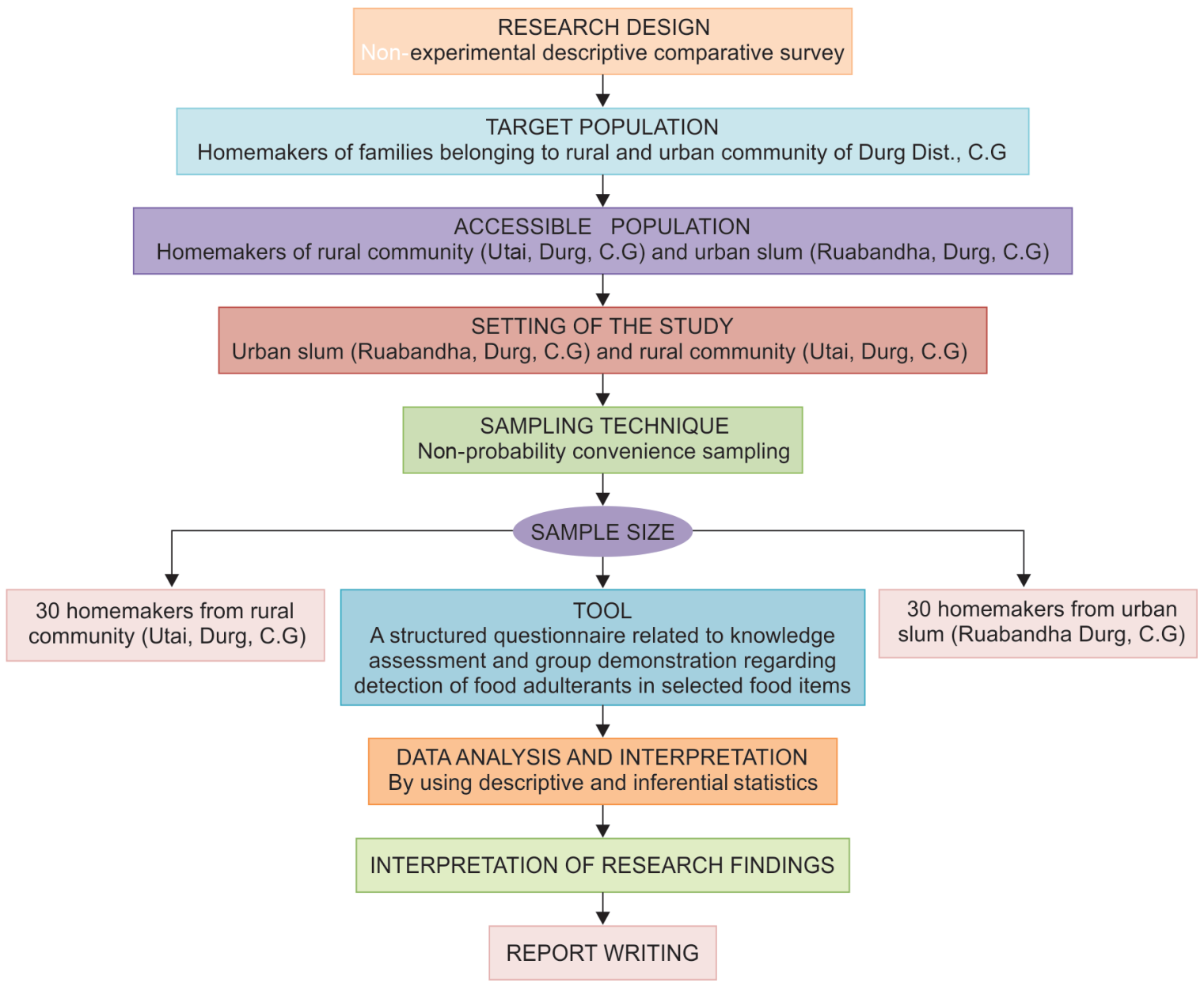

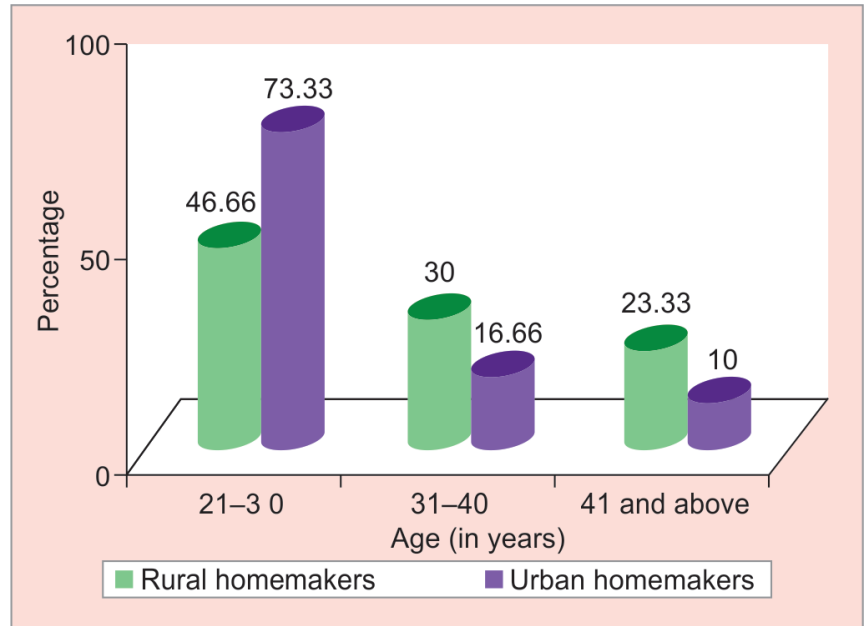

Fig. 1: Clustered cylindrical diagram showing percentage distribution of subjects according to age

Table 1 depicts that the calculated value of " $t$ " is 0.473 which is less than table value (2.00) at $p<0.05$; therefore, the difference

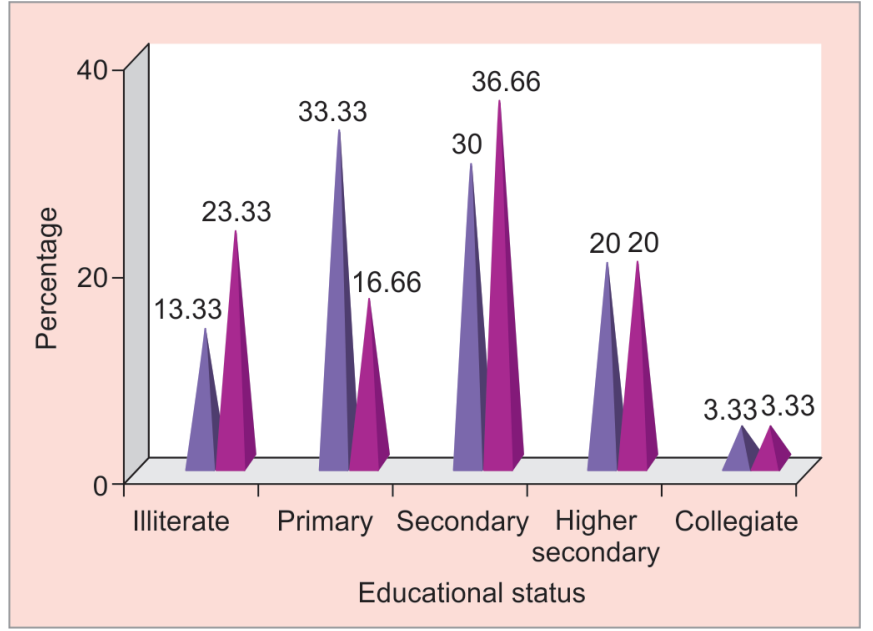

Fig. 2: Clustered cone diagram showing percentage distribution of subjects according to educational status

in mean scores of knowledge of rural and urban home makers is not significant. 


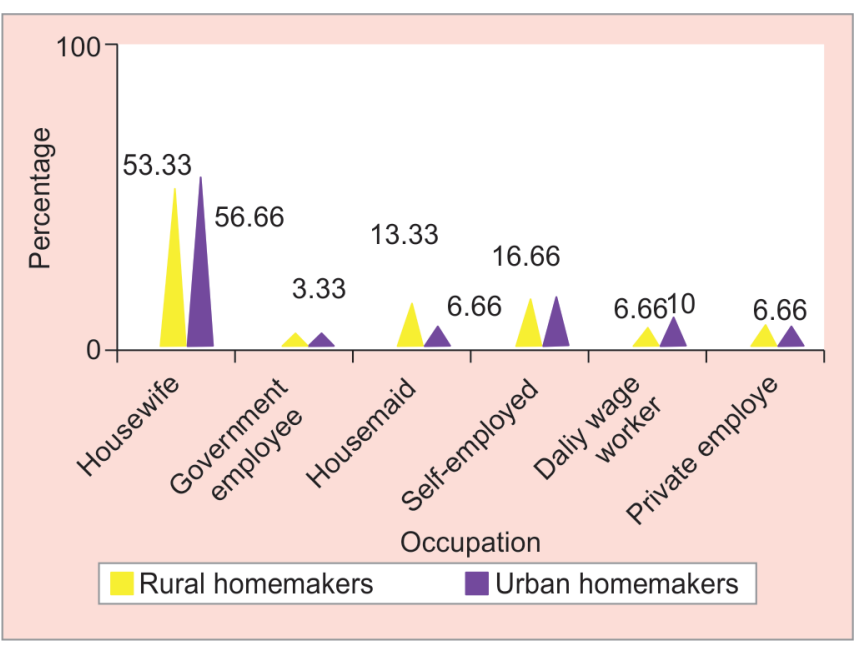

Fig. 3: Clustered cone diagram showing percentage distribution of subjects according to occupation

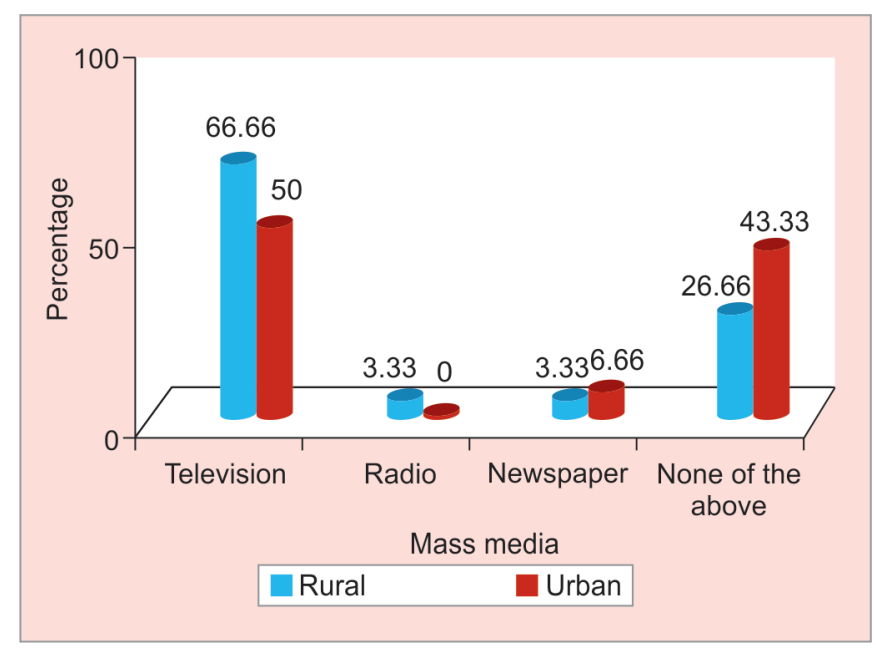

Fig. 5: Clustered cylindrical diagram showing percentage distribution of subjects according to type of mass media exposure

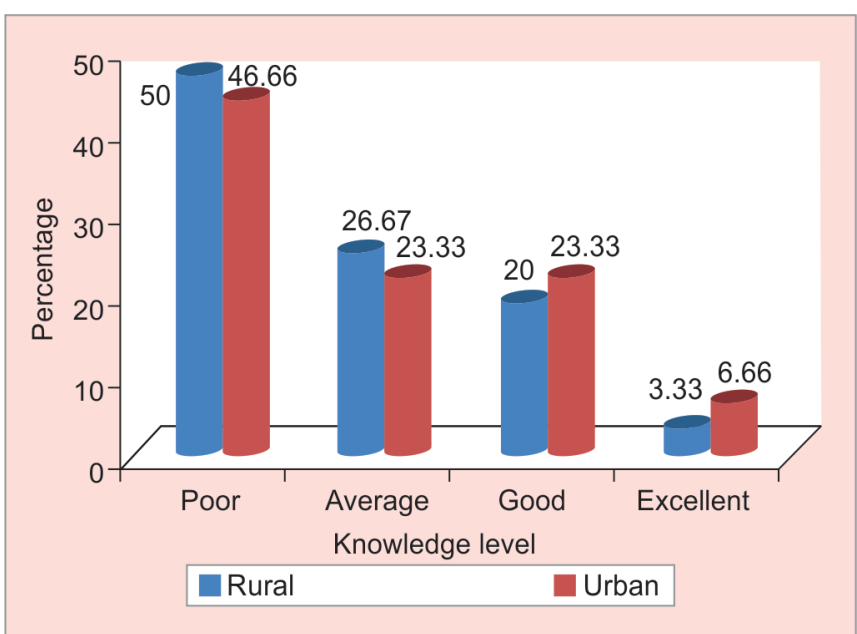

Fig. 7: Bar diagram showing percentage distribution of subjects according to knowledge level regarding food adulteration and its detection

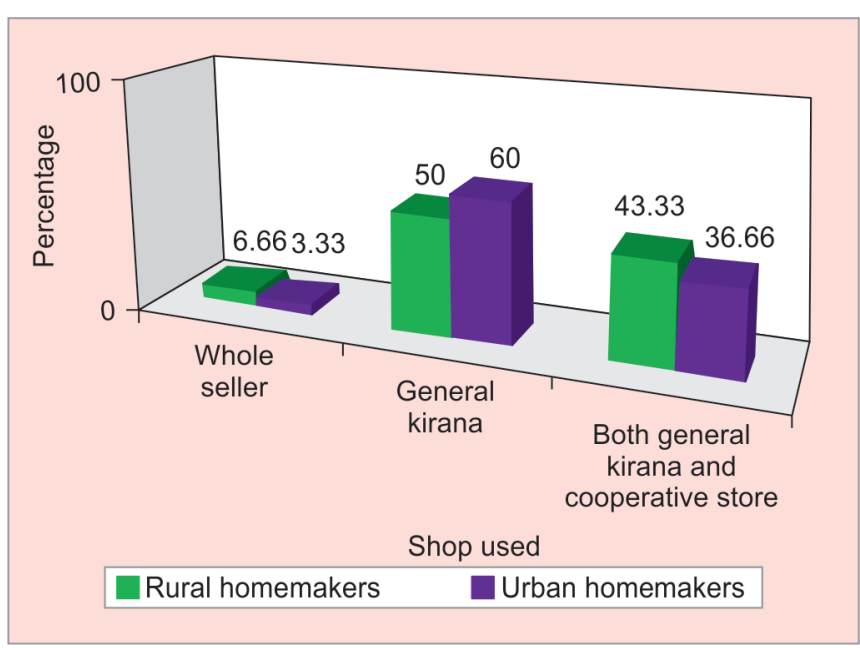

Fig. 4: Bar diagram showing percentage distribution of subjects according to shop used

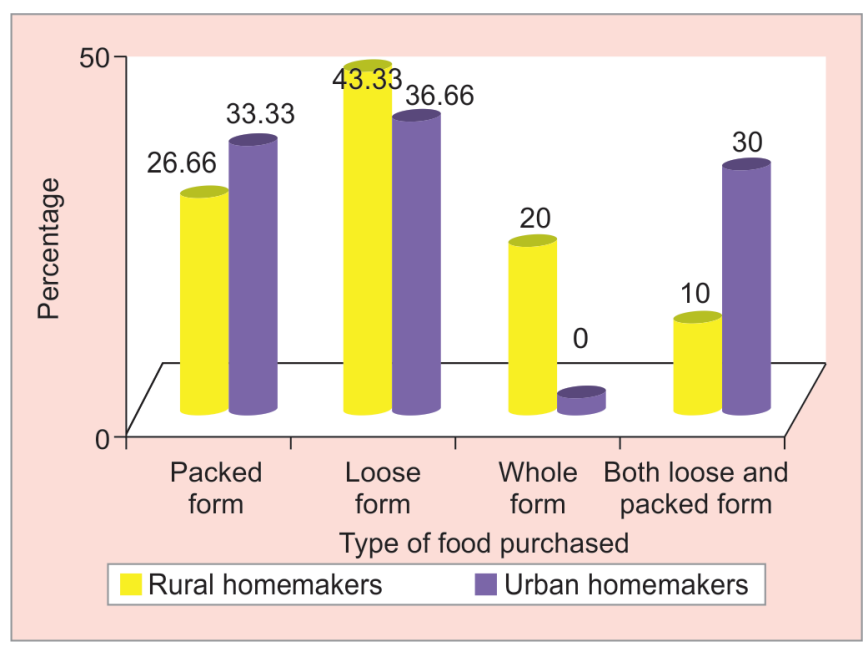

Fig. 6: Clustered cylindrical diagram showing percentage distribution of subjects according to type of food purchased

\section{Part IV-Association of Knowledge of the Rural and Urban Homemakers Regarding Food Adulteration and Its Detection with Selected Sociodemographic Variables}

Among rural homemakers, there is a significant association of knowledge level with education and occupation; whereas among urban homemakers, there is significant association of knowledge only with education.

Table 2 depicts that among rural homemakers, a significant association of knowledge with education is observed as the calculated value of $\chi^{2}(41.42)$ is greater than the table value (21.03), occupation as the calculated value of $\chi^{2}(33.8)$ is greater than table value (24.99) at $5 \%$ level of confidence and there is no association with age as the calculated value of $\chi^{2}$ (3.69) is less than the table value (11.07); whereas among urban homemakers, significant association of knowledge with education is observed as the calculated value of $\chi^{2}(27.41)$ is more than the table value (27.41) at $5 \%$ level of confidence, and there is no association of knowledge with age as calculated $\chi^{2}$ value (4.03) is less than the table value 
Table 1: Comparison of knowledge level of rural and urban homemakers regarding food adulteration and its detection

\begin{tabular}{|c|c|c|c|c|c|c|}
\hline & $\begin{array}{l}\text { Rural homemakers } \\
\left(n_{1}=30\right)\end{array}$ & $\begin{array}{l}\text { Urban homemakers } \\
\left(n_{2}=30\right)\end{array}$ & Calculated value of " $t$ " & $d f$ & $\begin{array}{l}\text { Critical value at } \\
p<0.05\end{array}$ & Inference \\
\hline $\begin{array}{l}\text { Mean knowledge } \\
\text { score }\end{array}$ & $X=12.86$ & $Y=13.4$ & 0.473 & 58 & 2.00 & Not significant \\
\hline
\end{tabular}

Table 2: Association of knowledge level with selected sociodemographic variables

\begin{tabular}{|c|c|c|c|c|c|c|c|c|}
\hline \multirow[b]{2}{*}{ Study variable } & \multicolumn{3}{|c|}{ Rural homemakers $\left(n_{1}=30\right)$} & \multirow[b]{2}{*}{ Inference } & \multicolumn{3}{|c|}{ Urban homemakers $\left(n_{2}=30\right)$} & \multirow[b]{2}{*}{ Inference } \\
\hline & $x^{2}$ & $d f$ & $\begin{array}{l}\text { Critical value at } \\
p<0.05\end{array}$ & & $x^{2}$ & $d f$ & $\begin{array}{l}\text { Critical value at } \\
p<0.05\end{array}$ & \\
\hline Age & 3.69 & 5 & 11.07 & Not significant & 4.03 & 5 & 11.07 & Not significant \\
\hline Education & 41.42 & 12 & 21.03 & Significant & 27.41 & 12 & 21.03 & Significant \\
\hline Occupation & 33.8 & 15 & 24.99 & Significant & 18.98 & 15 & 24.99 & Not significant \\
\hline
\end{tabular}

(11.07), occupation as calculated value of $\chi^{2}$ (18.98) is less than the table value (24.99) at $5 \%$ level of confidence.

\section{Part V-Assessment of Buying Practices and Awareness Regarding Food Safety Standard Symbols among Rural and Urban Homemakers}

Among rural homemakers, 13 (43.33\%) never purchased packed food. Fifteen (50\%) homemakers always checked MR. Twenty-one (70\%) never checked weight. Seventeen (56.66\%) homemakers always checked the manufacturing date. None of the homemakers checked the nutritional label ever. Among urban homemakers, 19 (63.33\%) occasionally purchased packed food, 11 (36.66\%) homemakers always checked MRP, 20 (66.66\%) never checked weight, 14 (46.66\%) never checked the manufacturing date. None of the homemakers checked nutritional label ever (Fig. 8). Among the rural homemakers, only 07 (23.33\%) were aware about food safety standard symbol; and among urban homemakers, 11 (36.66\%) were aware of food safety standard symbol (Fig. 9).

\section{IMPLICATIONS}

The findings of the study have implications for community nursing practice, nursing education, nursing administration, nursing research, and public health education.

\section{Community Nursing Practice}

- Community health nurse can spread information on various aspects of food quality and safety to consumers particularly in rural area with a view to enable them to adopt best food practices.

- Community health nurse can demonstrate to equip people with simple household techniques for identification of food adulterant in both rural and urban areas.

- Community health nurse can help in capacity building for community action by boosting confidence and capacity among community people particularly in rural area, e.g., mode of giving complaints to consumer forum, organizing petitions.

- Community health nurse can work with family to counsel and guide them regarding nutritional choices in terms of income, food habits, etc., in both rural and urban areas.

\section{Nursing Education}

- Nurse educators can take responsibility of organizing health camps to improve knowledge regarding purchasing and selection of food, food adulteration.

- Conduct workshops for community leaders, schoolteachers, Mahila Mandals, and other supportive staffs, making them aware of simple rapid tests for detection of adulterant and of consumer rights.

- Peer groups in both rural and urban areas can be selected for imparting knowledge to other group of people.

- Student nurses must be equipped with latest/recent information regarding food safety standards and Consumer Protection Act.

- Conduct interaction and teaching session with schoolchildren to improve knowledge regarding food safety standards and Consumer Protection Act.

\section{Nursing Administration}

In the event of ever growing challenges of implementing quality and standards in keeping with international standards and practices related to food, nurse administrators should facilitate continuing educational opportunities which enable to update skills and knowledge.

- Nurse administrators in coordination with national, state, local governments, nongovernmental organizations (NGOs), and mass media conduct motivational campaign to tackle the problems of food adulteration.

- Building community organizations such as cultural groups, street theaters to make people active in pursuing health objectives.

- Work and coordinate with welfare agencies, NGOs to make available and accessible the rapid test tool kit.

- Organize conferences, workshops, exhibitions to make people aware regarding food adulteration, its effects on health, and methods to detect it.

- Nurse administrators should promote and motivate for educational materials like leaflets, pamphlets, booklets, posters with information on toll-free numbers to lodge complaints.

- In coordination with the government, compulsory use of food products with standard symbols in nursing homes, student hostels, mid-day meal scheme centers should be implemented. 


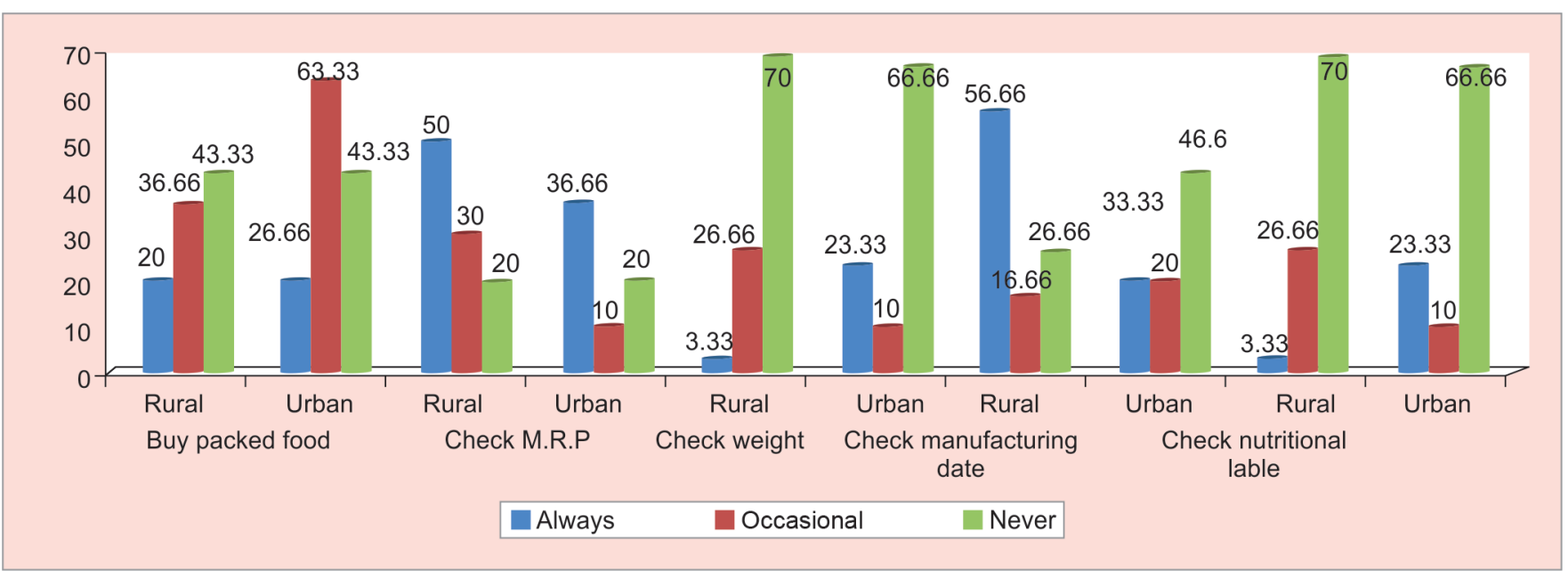

Fig. 8: Clustered cylindrical diagram showing percentage distribution of subjects according to buying practices

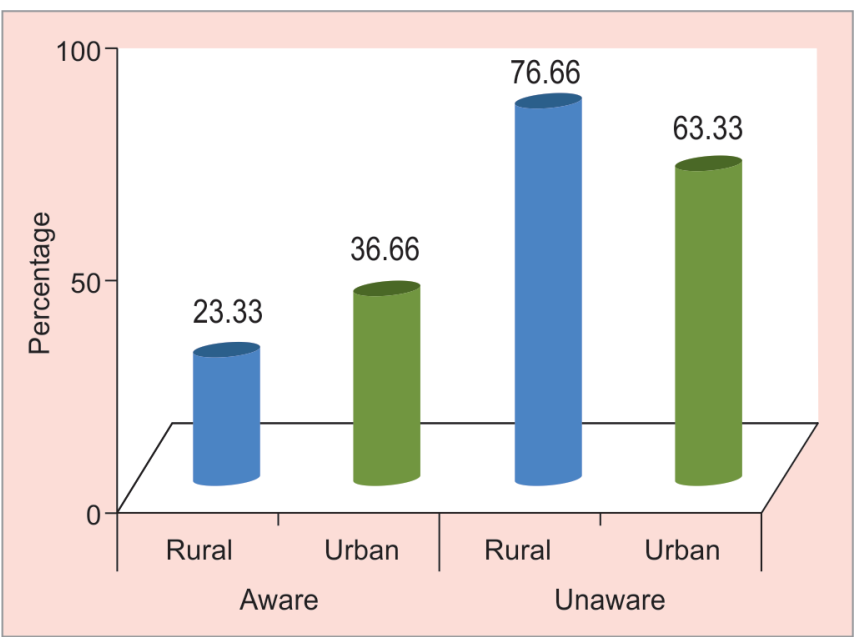

Fig. 9: Clustered cylindrical diagram showing percentage distribution of subjects according to awareness regarding food safety standard symbols

\section{Public Education}

- Manuals and charts can be prepared and exhibited at various common places such as schools, colleges, clinics, OPD factories.

\section{Nursing Research}

- Promoting involvement in research institutions, universities, and colleges in consumer protection and welfare.

\section{CONCLUSION}

Appropriate knowledge regarding food adulteration, its detection, and consumer protection is an important component of public health because good nutrition benefits everyone. A better informed public supported by effective health information would help people to make better food choices and prevent foodborne illnesses. Food safety and development of quality is joint responsibility of health professionals and consumers; hence, community health nurse plays a crucial role in creating awareness among the general public.

\section{References}

1. Crocker SHV. Real food matters for health. J Psychosoc Nurs Ment Health Serv 2010;48(10):48-54. DOI: 10.3928/02793695-2010083102.

2. Gupta K, Gupta LC, Gupta A. Food and nutrition: facts and figure. 5th ed., New Delhi: Jaypee Brothers' Medical Publishers (p) Ltd; 1999. p. 163.

3. Majumdar K. Essentials of human nutrition. 1st ed., New Delhi: Jaypee Brothers' Medical Publishers (p) Ltd; 1997. p. 42.

4. Sue WR. Essentials of nutrition and diet therapy. 6th ed., London: Mosby Publication; 2001. pp. 178-180.

5. Passmore R, Eastwood MA. Human nutrition and dietetics. 8th ed., Hong Kong: Churchill Livingstone Publication; 2005. p. 248.

6. Kamalam S. Essentials in community health nursing. 1st ed., New Delhi: Jaypee Brothers' Medical Publishers (p) Ltd; 1994. p. 521.

7. Indu S. Nutr Bull 2005;30(2):194-195.

8. Gupta N, Panchal P. Extent of awareness and food adulteration detection in selected food items purchased by homemakers. Pak J Nutr 2009;8(5):660. DOI: 10.3923/pjn.2009.660.667.

9. Yang L-X, Zhang G-X, Yang L-X, et al. LC-MS/MS determination of acrylamide in instant noodles from supermarkets in the Hebei Province of China. Food Addit Contam Part B Surveill 2012;5(2): 100-104. DOI: 10.1080/19393210.2012.658874.

10. Melanie ME, Evelyn WM. Theoretical basis for nursing. 2nd ed., Philadelphia: Lippincott Williams and Wilkins Publication; 2002. pp. 177-179.

11. Marilyn PE. Nursing theories and nursing practice. 2nd ed., Jaypee Brothers' Medical Publishers (p) Ltd; 2007. p. 239. 